\title{
Microencapsulation of an anthocyanin-rich blackberry (Rubus spp.) by-product extract by freeze-drying
}

\author{
Camila Yamashita ${ }^{\text {a, * }}$, Monique Mi Song Chung ${ }^{\text {b }}$, Catarina dos Santos a , \\ Cassia Roberta Malacrida Mayer ${ }^{\mathrm{a}}$, Izabel Cristina Freitas Moraes ${ }^{\mathrm{b}}$, \\ Ivanise Guilherme Branco ${ }^{\text {a }}$ \\ ${ }^{a}$ Universidade Estadual Paulista (UNESP), Faculdade de Ciências e Letras (FCL/UNESP), 19806-900, Assis, São Paulo, Brazil \\ ${ }^{\mathrm{b}}$ Universidade de São Paulo (USP), Faculdade de Zootecnia e Engenharia de Alimentos (FZEA/USP), 13635-900, Pirassununga, São Paulo, Brazil
}

\section{A R T I C L E I N F O}

\section{Article history:}

Received 19 December 2016

Received in revised form

24 May 2017

Accepted 25 May 2017

Available online 26 May 2017

\section{Keywords}

Anthocyanin

Blackberry by-product

Freeze-drying

Maltodextrin

Microencapsulation

\begin{abstract}
A B S T R A C T
One approach to improving sustainable food production is to add value to fruit by-products, which are currently used as animal feed or discarded, yet may be useful sources of natural antioxidants due to their phenolic compounds. Hence, the present work aimed to produce and evaluate two products prepared from an anthocyanin-rich extract of a blackberry by-product through freeze-drying. Maltodextrins with 10 and 20 dextrose equivalent (DE), were assessed as the carrier matrices. The maltodextrin DE did not significantly influence the mean diameter and solubility of the particles. Morphological analysis revealed that all the particles exhibited a broken glass structure and shriveled surfaces. Comparatively, better results were obtained from the maltodextrin 10 than 20DE powders, regarding anthocyanin retention in the drying process, hygroscopicity, moisture content, acidity, water activity and color indices $(\mathrm{P}<0.05)$. The results suggest that blackberry by-products contain valuable biocompounds, namely anthocyanins. Therefore, the anthocyanin extraction, concentration and microencapsulation with maltodextrin $10 \mathrm{DE}$, presented a potential approach to using blackberry byproducts as food colorants or healthy ingredients.
\end{abstract}

() 2017 Elsevier Ltd. All rights reserved.

\section{Introduction}

Studies have shown that agricultural and industrial by-products from berries and other fruits and vegetables are good sources of bioactive compounds (Balasundram, Sundram, \& Samman, 2006; Machado, Pasquel-Reátegui, Barbero, \& Martínez, 2015) that could be used as nutraceuticals (Gorinstein et al., 2011). From an economical perspective, it is interesting to recover agro-industrial by-products as raw material for processing new food, pharmaceutical and cosmetics, which might enable a sustainable industrial production system, adding value to a food waste and reducing its disposal into the environment (Machado et al., 2015). Blackberries are increasing in economic value because of their high nutritional value and benefits to physical and mental health (Franceschinis, Salvatori, Sosa, \& Schebor, 2014; Ivanovic et al., 2014), which can be largely attributed to their phenolic compounds, such as phenolic

\footnotetext{
* Corresponding author.

E-mail address: ca_yamashita@msn.com (C. Yamashita).
}

acids, tannins and anthocyanins (Branco et al., 2016; Kaume, Howard, \& Devareddy, 2011).

Anthocyanins are water-soluble pigments, responsible for the red to purple shades of plant foods (Laokuldilok \& Kanha, 2015). This group of phenolic compounds is associated with a high antioxidant activity, hence, the consumption of plant foods containing anthocyanins is linked to prevention of cardiovascular and neurological diseases, cancer and diabetes (Branco et al., 2016; Konczak \& Zhang, 2004). Moreover, anthocyanins could be a good substitute for synthetic pigments. However, anthocyanins are unstable due to their sensitivity to temperature, $\mathrm{pH}$, light and oxygen, for example (Patras, Brunton, O'Donnell, \& Tiwari, 2010). Consequently, the food industry is constantly searching for practical and economical methods of conserving the color and bioactive properties of anthocyanins. Freeze-drying is considered a suitable method for drying heat-sensitive pigments. It is based on dehydration by sublimation of a frozen product and, during this procedure, the core materials and matrix solutions are homogenized and then colyophilized, resulting in a dry material (Laokuldilok \& Kanha, 2015; Wilkowska, Ambroziak, Czyżowska, \& Adamiec, 2016). 
Another technology which has been used to protect sensitive materials is encapsulation, which consists of packaging materials in the form of micro- or nanoparticles (Jafari, Assadpoor, He, \& Bhandari, 2008). The choice of coating material is very important because it may influence the encapsulation efficiency and stability of the capsules (Wilkowska et al., 2016). Maltodextrin (MD) is the most commonly used encapsulating agent, due to its high water solubility, low viscosity and low sugar content (Bakowska-Barczak \& Kolodziejczyk, 2011). MDs with a dextrose equivalent (DE) between 10 and 20 are widely used to encapsulate anthocyanins and phenolic acids (Ahmed, Akter, Lee, \& Eun, 2010; Silva, Constant, Figueiredo, \& Moura, 2010; Tonon, Brabet, \& Hubinger, 2010).

In this context, the objective of the present work was to use freeze-drying and MD (10 and 20DE) as the carrier agent, to encapsulate a concentrated anthocyanin extract isolated from a blackberry (Rubus spp.) by-product and to evaluate the physicochemical properties of the obtained microparticles.

\section{Material and methods}

\subsection{Anthocyanin extraction}

Frozen blackberry pulp by-product (moisture 56.1\% and 5.0\% soluble solids) was provided by Ricaeli Company located in the city of Cabreúva, São Paulo, Brazil. It was stored in a freezing chamber at $-10{ }^{\circ} \mathrm{C}$ and thawed in a refrigerator $\left(7-8{ }^{\circ} \mathrm{C}\right)$ for $24 \mathrm{~h}$.

Water was added at a 1:3 by-product-to-water $(\mathrm{m} / \mathrm{v})$ ratio, and the mixture shaken at room temperature in the dark for $8 \mathrm{~h}$. The extract was then filtered through a sieve and concentrated using a rotatory evaporator at $60{ }^{\circ} \mathrm{C}$, until $1 / 3$ of the initial volume remained (Souza, Thomazini, Balieiro, \& Fávaro-Trindade, 2015). The concentrated extract was stored in dark glass recipients in the fridge, until analysis.

\subsection{Microencapsulation of anthocyanin extract by freeze-drying}

MDs (10 and 20DE; Cargill Inc., Brazil) were respectively added to the concentrated extract to obtain $30 \%$ total solids concentration, followed by mechanical homogenization. The mixtures were then freeze-dried using a lyophilizer (Liotop L101, São Carlos, Brazil) at a constant temperature of $-20{ }^{\circ} \mathrm{C}$. The dried samples were ground using a mortar and pestle and the powders were packed in polyethylene bags and stored in the dark, until further analysis.

\subsection{Characterization of the anthocyanins extract}

The concentrated anthocyanin extract and the freeze-dried powders were characterized for their soluble solids ( ${ }^{\circ}$ Brix) by refractometry, $\mathrm{pH}$ using a $\mathrm{pH}$ meter, and acidity, based on titrimetric analysis with $\mathrm{NaOH}$ solution $(0.1 \mathrm{~N})$, as described by the Association of Official Analytical Chemists (AOAC, 2000).

\subsection{Total anthocyanin content}

The total anthocyanin content of the aqueous and concentrated extracts, as well as the lyophilized powders, was determined according to Fuleki and Francis (1968). The extraction was performed with 95\% ethanol and $1.5 \mathrm{~N} \mathrm{HCl}$ (85:15). Spectrophotometric absorbance (Biospectro Sp-220, Equipar, Curitiba, Brazil) was measured at $535 \mathrm{~nm}$. The results were expressed as mg of cyanidin 3 -glucoside/100 $\mathrm{g}$ of sample (dry basis). The retention of the anthocyanins after concentration and freeze-drying was also calculated.

\subsection{Characterization of the microcapsules}

\subsubsection{Moisture content and water activity $\left(a_{w}\right)$}

The moisture content of the powder was determined gravimetrically. Samples were weighed and dried in an oven, with air circulation, at $105{ }^{\circ} \mathrm{C}$ for $24 \mathrm{~h}$ (AOAC, 2000). The $\mathrm{a}_{\mathrm{w}}$ was measured in an Aqualab CX-2 (Decagon, Pullman, USA) hygrometer, at $25^{\circ} \mathrm{C}$.

\subsubsection{Hygroscopicity}

The hygroscopicity of the powdered samples was assessed according to Tonon, Brabet, and Hubinger (2008), with modifications. Samples of each powder were stored at $20{ }^{\circ} \mathrm{C}$, in desiccators containing saturated sodium chloride $(\mathrm{NaCl})$ solutions (75\% relative humidity; $a_{w}=0.75$ ). The samples were weighed after 1 week, and the hygroscopicity was expressed as grams of absorbed moisture per $100 \mathrm{~g}$ of dry solids (g/100 g).

\subsubsection{Solubility}

Powder solubility was evaluated based on the method described by Cano-Chauca, Stringheta, Ramos, and Cal-Vidal (2005), with some modifications. The powder $(0.5 \mathrm{~g})$ was dissolved in $50 \mathrm{~mL}$ of distilled water and stirred at room temperature for $30 \mathrm{~min}$. The suspension was then transferred to a tube and centrifuged at $3000 \mathrm{~g}$ for $5 \mathrm{~min}$. An aliquot $(25 \mathrm{~mL})$ of the supernatant was transferred to a pre-weighed Petri dish and dried at $105{ }^{\circ} \mathrm{C}$ for $5 \mathrm{~h}$. After drying, the dried weight of the soluble solid was measured and used to calculate the percentage solubility.

\subsubsection{Color measurement}

The color of the blackberry powder was measured using a colorimeter (HunterLab MiniScan EZ, Reston, USA), with a CIE Lab scale $\left(L^{*}, a^{*}\right.$ and $\left.b^{*}\right)$. The color measurements were expressed in terms of lightness $\mathrm{L}^{*}$ [0 (black) to 100 (white)] and the chromaticity parameters $\mathrm{a}^{*}$ [green $(-)$ to red $(+)$ ] and $\mathrm{b}^{*}$ [blue $(-)$ to yellow $(+)$ ]. The chroma $\left(\mathrm{C}^{*}\right)$ or color intensity, and hue angle $\left(\mathrm{H}^{\circ}\right)\left[0^{\circ}\right.$ (pure red color), $90^{\circ}$ (pure yellow color), $180^{\circ}$ (pure green color) and $270^{\circ}$ (pure blue color)], were calculated by using Eqs. (1) and (2), respectively. The measurements were performed in triplicate and three readings were done for each replicate.

$\mathrm{C} *=\left[(\mathrm{a})^{2}+(\mathrm{b})^{2}\right]^{1 / 2}$

Hue angle $\left(^{\circ}\right)=\tan ^{-1}\left(\frac{\mathrm{b} *}{\mathrm{a} *}\right)$

\subsubsection{Particle morphology and size distribution}

The microstructure of both freeze-dried powders was evaluated by scanning electron microscopy (SEM) (Topcon SM300, Tokyo, Japan), according to Tonon et al. (2008). The powders were attached to double-sided adhesive tape, fixed to SEM stubs and coated with gold/palladium, at a coating rate of $0.51 \AA / \mathrm{s}, 3-5 \mathrm{~mA}, 1 \mathrm{~V}$ and $2 \times 10^{-2}$ Pa for $180 \mathrm{~s}$. The SEM was operated at $5 \mathrm{kV}$ with a magnification of 500 and $1000 \times$. The particle size was determined using a laser light diffraction instrument (Shimadzu Sald-201V, Tokyo, Japan). A small amount of powder was suspended in isopropanol under magnetic agitation, and the particle size distribution was monitored until successive readings became constant. The particle size was expressed as $\mathrm{D}[4,3]$, also known as the De Brouckere mean diameter, which is the volume mean diameter and is generally used to characterize a particle. 


\subsection{Statistical analysis}

Data were statistically analyzed using analysis of variance $(P<0.05)$. Tukey's test $(P<0.05)$ was used to assess significant differences between the samples. All statistical tests were done using Statistica 5.0 (StatSoft, Tulsa, OK, USA). All experiments were performed in triplicate and the data reported as mean values \pm standard deviation.

\section{Results and discussion}

\subsection{Effect of concentration and carrier agent on physicochemical characteristics and anthocyanin content}

With the intention to develop a future food industrial use for blackberry by-product, it was important to choose a simple and low-cost method, with low toxicity extractors, to perform the anthocyanin extraction. Therefore, an aqueous extraction was performed, followed by evaporation, increasing the soluble solids content from $2.05 \pm 0.08^{\circ}$ Brix in the aqueous extract to $8.08 \pm 0.55$ ${ }^{\circ}$ Brix in the concentrate. These latter values were comparable to those reported by Tadeu et al. (2015) (9.05-11.52 ${ }^{\circ}$ Brix), Souza et al. (2015) (10.17 ${ }^{\circ}$ Brix) and Ferrari, Germer, and Aguirre (2012) (6.77 ${ }^{\circ}$ Brix), studying the fruit pulp.

Regarding the total anthocyanin content, the values were significantly lower for both microencapsulated powders when compared to the original extract. The retention percentages were 54,76 and $68 \%$ (Table 1 ) for the concentration process, and freezedrying with MD of 10 and 20DE, respectively. The anthocyanin degradation rate is reported to increase with increasing solid content during heating, which could be due to the closeness of reacting molecules in juice with a higher soluble solid content (Nielsen, Marcy, \& Sadler, 1993). Also, in Hou, Qin, Zhang, Cui, and Ren's study (2013), it was concluded that anthocyanins are more stable at a lower temperature (around $80^{\circ} \mathrm{C}$ ), lower $\mathrm{pH}$ values and shorttime. In the present study, the concentration process was carried out at $60{ }^{\circ} \mathrm{C}$ under vacuum, however, the heat exposure duration (around $3 \mathrm{~h}$ ) may have contributed to the anthocyanin degradation. Recently, Branco et al. (2016) demonstrated that a 5 min pasteurization at $70^{\circ} \mathrm{C}$ of jambolan (Syzygium cumini (L.) Skeels) fruit pulp, led to an anthocyanin decrease of $9 \%$, when compared with the unpasteurized pulp, showing that even a mild heat treatment results in degradation of the phytochemical. Therefore, the operational parameters used in the concentration of the anthocyanins extract, such as the magnitude and duration of heating, can be modified, which could lead to a higher retention of polyphenols.

Polyphenols can also be degraded by exposure to oxygen and light (Patras et al., 2010). Hence, microencapsulation could be a good way to preserve the anthocyanins after thermal treatment. Thus, the concentrated extract was respectively encapsulated using MD of 10 and 20DE. After encapsulation of the concentrate, MD 10DE showed a significantly higher retention of the anthocyanins than MD 20DE, highlighting the influence of DE on the retention of the anthocyanins (Table 1). Kuck and Noreña (2016) found

Table 1

Anthocyanin content (dry basis) for aqueous extract, concentrate and powders.

\begin{tabular}{ll}
\hline & Total Anthocyanin (mg cyd 3-glu/100 g db) \\
\hline Aqueous Extract & $718.47 \pm 56.07^{\mathrm{a}}$ \\
Concentrate & $389.09 \pm 2.91^{\mathrm{b}}$ \\
$10 \mathrm{DE}$ & $297.86 \pm 0.61^{\mathrm{c}}$ \\
$20 \mathrm{DE}$ & $265.73 \pm 0.69^{\mathrm{d}}$
\end{tabular}

Values expressed as mean \pm standard deviation; Different letters (a-d) indicate significant difference between $10 \mathrm{DE}$ and 20DE powders $(\mathrm{P}<0.05)$.
80.75-99.58\% retention of anthocyanins in grape skin extract encapsulated with different carrier agents (gum arabic, partially hydrolyzed guar gum and polydextrose) by freeze and spray drying.

The anthocyanin retention difference between the techniques of spray- and freeze-drying using MD have been previously described by Franceschinis et al. (2014), in freeze-dried (162 mg/100 g) and spray-dried (70 mg/100 g) blackberry juice. Saikia, Mahnot, and Mahanta (2015) also found a higher efficiency in the freeze-dried (78-97 \%) than spray-dried (63-79\%) samples. Phenolic losses in the spray-drying process are linked to the large surface area exposed to air (Oberoi \& Sogi, 2015) and high temperatures, whereas, the loss during freeze-drying is associated with material grinding after the lyophilization (Kuck \& Noreña, 2016).

The current findings indicate that the freeze-dried blackberry by-product, using MD as the coating material, is an interesting alternative to maintaining anthocyanin stability during encapsulation, producing a powder with a high level of this polyphenol. These results are also in agreement with those of Jafari, MahdaviKhazaei, and Hemmati-Kakhki (2016) that recommended microencapsulation by freeze-drying as a suitable method for stabilizing anthocyanins of saffron petals. Saikia et al. (2015) also verified a high encapsulating efficiency by freeze-drying of phenolic extracts from star fruit (Averrhoa carambola) pomace coated with MD (20DE).

A significant difference between the concentrated and encapsulated anthocyanin extracts, regarding $\mathrm{pH}$ and titratable acidity, was verified (Table 2 ). The acidity of the concentrate was inversely correlated to the $\mathrm{pH}$. The addition of MD led to an increase in $\mathrm{pH}$ and a reduction in titratable acidity. Similar results have been reported for pure soursop pulp and pulp treated with MD (Ceballos, Giraldo, \& Orrego, 2012). Among the encapsulated samples, that with a higher total titratable acidity (Table 2), possessed a higher anthocyanin content (Table 1) after freeze-drying, indicating the influence of acidity and carrier agents on anthocyanin retention. The $\mathrm{pH}$ of the anthocyanin concentrate was similar to that found in blackberry pulp (Tosun, Ustun, \& Tekguler, 2008), and the total titratable acidity values also agreed with data from previous comparative reports (Ferrari et al., 2012; Franceschinis et al., 2014). As above-mentioned, anthocyanins are more stable at low $\mathrm{pH}$ values and the $\mathrm{pH}$ values found in this study were within a suitable $\mathrm{pH}$ range of anthocyanin stability, based on Gauche, Malagoli, and Luiz (2010).

\subsection{Moisture content and $a_{w}$}

The results showed that the moisture contents of both anthocyanin powders were around 5\%. However, statistical analysis revealed that the moisture content decreased with an increase in $\mathrm{DE}$ of the MD. The moisture content of a particular food is usually associated with its stability, quality and composition, and could affect its storage, packaging and processing. For the freeze-dried powders, when values of moisture content decline to around 5\% (wet basis), it causes a reduction in the perishability of the product (Tonon et al., 2010). Moisture content is different from $\mathrm{a}_{\mathrm{w}}$, as the

\section{Table 2}

$\mathrm{pH}$ and titulometric acidity of concentrated anthocyanin extract with and without maltodextrin.

\begin{tabular}{lll}
\hline & $\mathrm{pH}$ & Total acidity (\% citric acid) \\
\hline Concentrate & $3.27^{\mathrm{a}}$ & $0.94 \pm 0.006^{\mathrm{a}}$ \\
Concentrate $+10 \mathrm{DE}$ & $3.34^{\mathrm{b}}$ & $0.72 \pm 0.010^{\mathrm{b}}$ \\
Concentrate $+20 \mathrm{DE}$ & $3.29^{\mathrm{c}}$ & $0.69 \pm 0.006^{\mathrm{c}}$ \\
\hline
\end{tabular}

Values expressed as mean \pm standard deviation; Different letters in the same column indicate significant difference between $10 \mathrm{DE}$ and 20DE powders $(\mathrm{P}<0.05)$. 
latter measures the availability of free water in a food system that is responsible for any biochemical reactions, whereas the moisture content represents the water composition in a food system (Fazaeli, Emam-Djomeh, Ashtari, \& Omid, 2012). The higher the $a_{w}$, the more free water available for biochemical reactions and, hence, a shorter shelf life is predicted. The average $a_{w}$ of the powders in this study ranged from 0.51 to 0.53 . Thus, they can be considered relatively stable against microbial growth, and hydrolytic and enzymatic reactions because an $\mathrm{a}_{\mathrm{w}}<0.6$ is considered to be microbiologically stable (Quek, Chok, \& Swedlund, 2007). The $\mathrm{a}_{\mathrm{w}}$ values obtained, concurred with that provided by Caliskan and Dirim (2016) for freeze-dried sumac extract $\left(0.41 \mathrm{a}_{\mathrm{w}}\right)$ and Rocha-Parra, Lanari, Zamora, and Chirife (2016) (0.58 $\left.\mathrm{a}_{\mathrm{w}}\right)$, studying freeze-dried encapsulated red wine.

\subsection{Color analysis}

Color reflects the sensory attractiveness and is an important quality factor for dried foods, particularly for products like blackberry, which is also used as a colorant. Thus, to make food products marketable, the color of the supplemented products should ideally remain unchanged after production. The color coordinates determined for the MD 10 and 20DE blackberry by-product powders (Table 3), revealed that the microcapsules formulated with MD of $10 \mathrm{DE}$ were darker and had a deeper red (greater $\mathrm{a}^{*}$ value) than the 20DE microcapsules that had a higher $\mathrm{L}^{*}$ and lower $\mathrm{a}^{*}$ values. Jiménez-Aguilar et al. (2011) reported that the $\mathrm{a}^{*}$ coordinate is attributed to the anthocyanin content of the fruit, which is responsible for the redness of the blackberry by-product microcapsules. A lower $b^{*}$ value for encapsulated blackberry by-product represents greater yellowness. The lightness $\left(\mathrm{L}^{*}\right)$ revealed that the powder formulated with MD of 20DE, was lighter in color than that prepared with the 10DE MD. The possible reason for the lightness could be the destruction of anthocyanins in the process, as Saikia et al. (2015) associated the reduction of pigment with lighter samples.

The difference in $\mathrm{DE}$ between the MDs, significantly affected the tonality $\left(\mathrm{H}^{\circ}\right)$ and saturation $\left(\mathrm{C}^{*}\right)(\mathrm{P}<0.05)$. Therefore, the encapsulated powders formulated with 10DE compared to 20DE MD, showed greater color intensity as well as a more intense redness, concluding that the higher the $\mathrm{DE}$, the greater the anthocyanin loss.

\subsection{Hygroscopicity}

Hygroscopic studies of powdered foods are important because it can affect the food stickiness and caking when exposed to moisture during storage and distribution (Syamaladevi, Insan, Dhawan,

Table 3

Physical properties for encapsulated anthocyanin powders produced with different carrier agents.

\begin{tabular}{lll}
\hline & $10 \mathrm{DE}$ & $20 \mathrm{DE}$ \\
\hline Moisture content (\%) & $4.97 \pm 0.16^{\mathrm{a}}$ & $5.52 \pm 0.04^{\mathrm{b}}$ \\
Solubility(\%) & $44.78 \pm 0.63^{\mathrm{a}}$ & $44.86 \pm 0.11^{\mathrm{a}}$ \\
Hygroscopicity & $11.27 \pm 0.12^{\mathrm{a}}$ & $13.00 \pm 0.17^{\mathrm{b}}$ \\
Water activity & $0.51 \pm 0.003^{\mathrm{b}}$ & $0.53 \pm 0.002^{\mathrm{a}}$ \\
Color indices & & \\
$\mathrm{L}^{*}$ & $34.34 \pm 0.57^{\mathrm{b}}$ & $41.94 \pm 0.28^{\mathrm{a}}$ \\
$\mathrm{a}^{*}$ & $20.96 \pm 0.08^{\mathrm{a}}$ & $18.84 \pm 0.20^{\mathrm{b}}$ \\
$\mathrm{b}^{*}$ & $6.51 \pm 0.06^{\mathrm{a}}$ & $4.01 \pm 0.05^{\mathrm{b}}$ \\
$\mathrm{C}^{*}$ & $21.94 \pm 0.09^{\mathrm{a}}$ & $19.26 \pm 0.21^{\mathrm{b}}$ \\
$\mathrm{H}^{*}$ & $0.30 \pm 0.00^{\mathrm{a}}$ & $0.21 \pm 0.00^{\mathrm{b}}$ \\
Mean diameter D[4,3]( $\mu \mathrm{m})$ & $100.77 \pm 1.47^{\mathrm{a}}$ & $98.99 \pm 1.33^{\mathrm{a}}$ \\
\hline
\end{tabular}

Values expressed as mean \pm standard deviation; Different letters $(a-b)$ in the same line indicate significant difference between $10 \mathrm{DE}$ and 20DE powders $(\mathrm{P}<0.05)$.
Andrews, \& Sablani, 2012). The encapsulated anthocyanin powder of blackberry by-products with MD of 10DE was less hygroscopic than 20DE, indicating that the difference in the DE has an influence on hygroscopicity (Table 3), corroborating with Nayak and Rastogi (2010).

MDs with a lower DE have a higher percentage of long-chain oligosaccharides, so higher molecular weight. Thus, the 20DE MD is more hydrolyzed and the presence of a higher number of ramifications, with their hydrophilic groups, readily absorb water, contributes to degradation reactions, resulting in a higher hygroscopicity (Mahdavi, Jafari, Assadpoor, \& Dehnad, 2016; Tonon et al., 2010, 2011).

This may have favored anthocyanin oxidation (Paim, Costa, Walter, \& Tonon, 2016). The hygroscopicity values found in this work agreed with those found by Silva et al. (2010) (13.85-14.8\%) for jaboticaba peel extracts powders with MD, gum arabic and modified starch. Also, comparable values were documented by Kuck and Noreña (2016) (11.67-16.61\%), for grape skin powder produced with gum arabic, partially hydrolyzed guar gum and polydextrose. This latter study highlighted that a lower hygroscopicity, as found for freeze-dried powders, can be due to the larger particle size when compared with the spray-dried product (Man, Irwandi, \& Abdullah, 1999) because the larger the particle size, the lower the exposed surface area and, consequently, the lower the water absorption (Tonon et al., 2010).

\subsection{Morphology}

As shown in Fig. 1, the external morphology of the freeze-dried microparticles resembled a broken glass structure of variable sizes, which are all common features of freeze-dried powders (Franceschinis et al., 2014; Kuck \& Noreña, 2016; Rocha-Parra et al., 2016; Saikia et al., 2015). This glassy structure, with an irregular shape, might protect the anthocyanins against heat and oxygen exposition (Roos, 1995). The micrographs also showed that MD 20DE in the wall formula, caused more friability of the solids and produced smaller particles than the microcapsules containing MD 10DE.

Fig. 2 presents the size distribution of both particles. It was observed that the 10 and 20DE MD powders showed three distinct peaks, each one representing a predominant size, with particle diameters varying from 7.0 to $127.0 \mu \mathrm{m}$. Tonon et al. (2010) prepared spray-dried açaí juice powder, with the same carrier agents and obtained particles (median diameter: 10DE $=10.08 \mu \mathrm{m}$; $20 \mathrm{DE}=9.01 \mu \mathrm{m}$ ) that were 10 -fold smaller in size than those found in the current study. Conversely, Kuck and Noreña (2016) achieved similar sizes in grape skin phenolic extract encapsulation (104.3-684.9 $\mu \mathrm{m})$ using freeze-drying. This difference was expected because the particle diameter of spray-dried products ranges from 1 to $15 \mu \mathrm{m}$, whereas freeze-dried products can reach $300 \mu \mathrm{m}$ (Man et al., 1999).

The mean particle diameter for the two different wall matrices presented in Table 3, shows that the particles produced with MD 10DE exhibited a mean diameter slightly higher than the 20DE but the difference was not significant. Therefore, the carrier agent did not influence the particle size. These results concur with Tonon et al. (2010), verifying a higher particle size for microcapsules formulated for 10 than 20DE MD, which the authors associated with the longer chains of 10DE MD, as a consequence of its lower degree of hydrolysis. With regard to the solubility, MD is highly water-soluble (Souza et al., 2015). However, low solubility values were found for both 10 and 20DE MD, without significant differences between them (Table 3). The results corresponded to the observations of Saikia et al. (2015), in the microencapsulation of A. carambola pomace (42-45\%, spray-dried; $60-64 \%$, freeze-dried) 

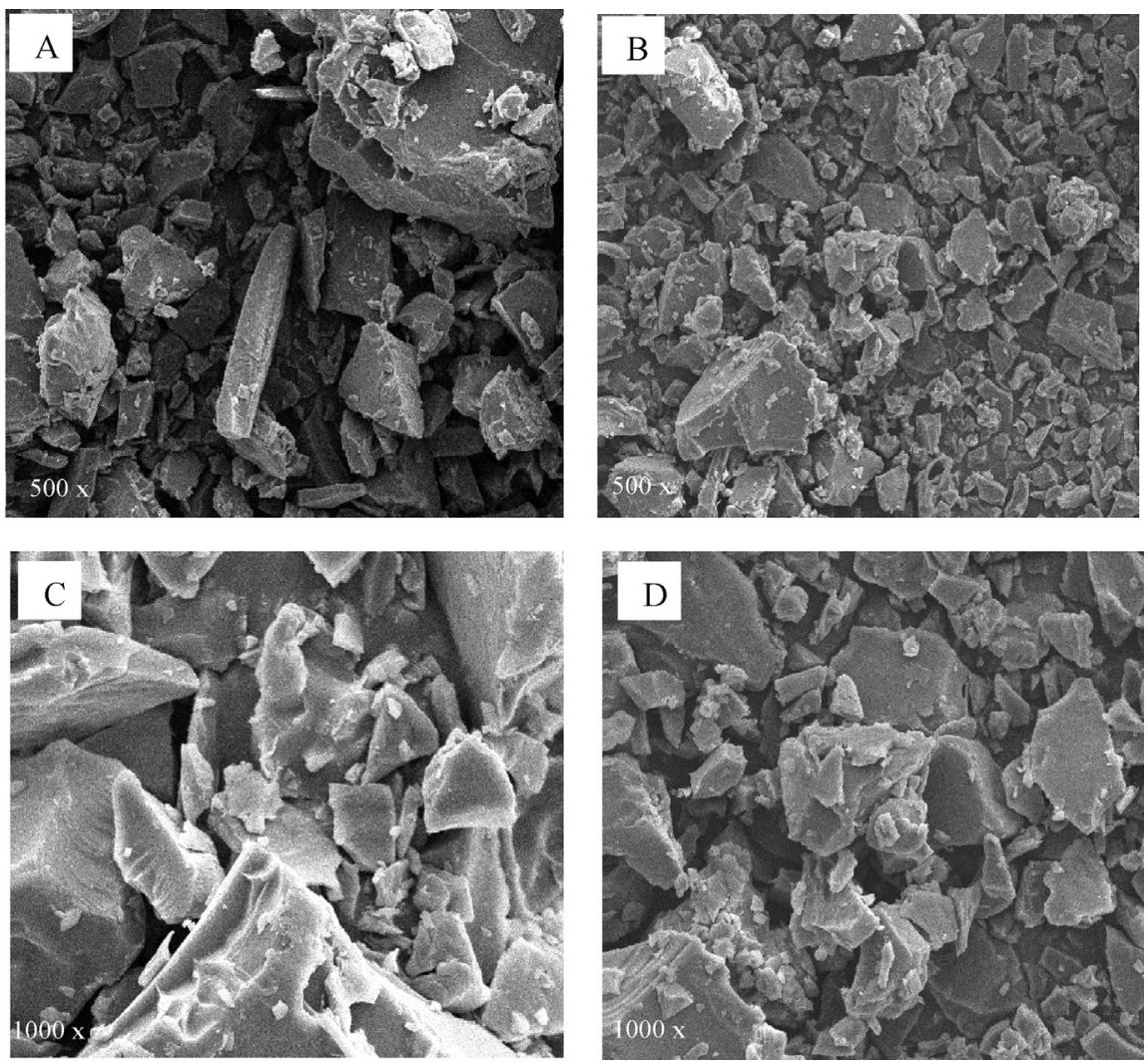

Fig. 1. Scanning electron micrographs of freeze-dried microencapsulated anthocyanins powders with A and C: maltodextrin 10DE; B and D: maltodextrin 20DE.

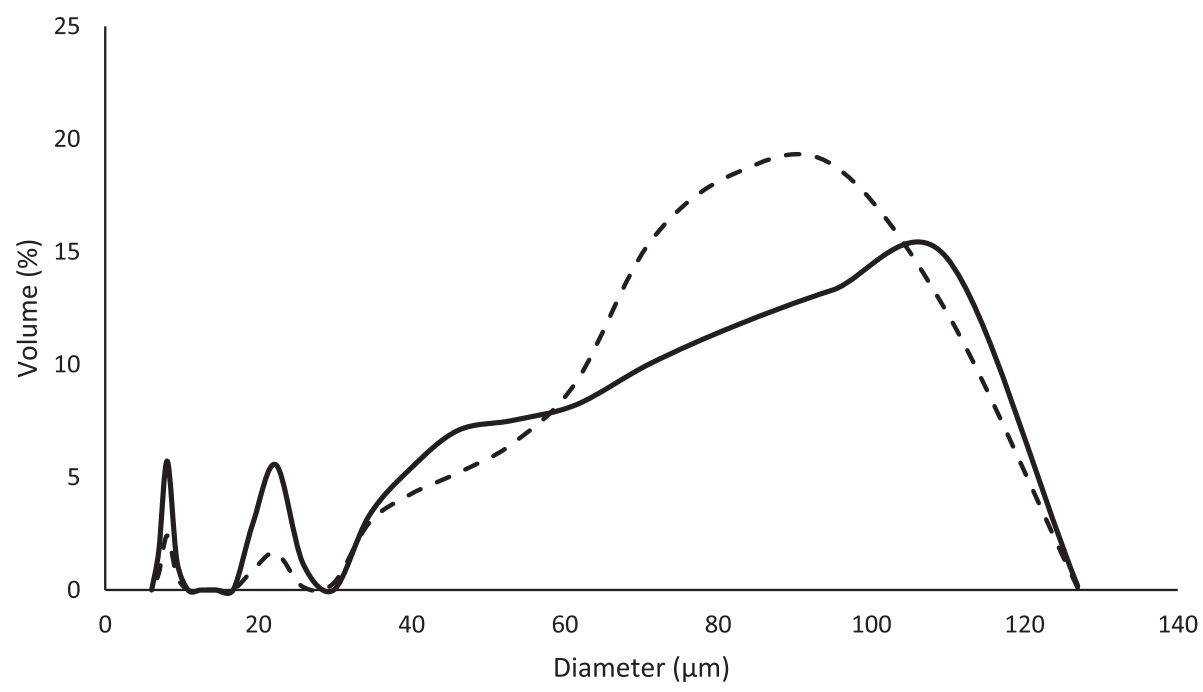

Fig. 2. Particle size distribution of powders produced with different carrier agents (— $10 \mathrm{DE}$; - - - 20DE).

using MD ( $\leq 20 \mathrm{DE})$, as the carrier agent but considerably higher than Souza, Gurak, and Marczak (2017), for jaboticaba pomace encapsulated with various agents by freeze-drying (15.09-21.28\%). Chen, Chi, and Xu (2012) explained that the large particle size of freeze-dried samples is caused by the low-temperature process and the lack of strength necessary to break the frozen drops or to alter the surface during drying. This large size might influence the solubility because a higher solubility may be associated with smaller particle size because of its greater surface area available for hydration (Kuck \& Noreña, 2016).

\section{Conclusions}

This study indicated that freeze-drying efficiently encapsulated a concentrated anthocyanin extract obtained from blackberry byproducts, with a high anthocyanin retention (76\% for 10DE MD; $68 \%$ for 20DE MD). The powders exhibited irregular broken glass particles, which is characteristic of particles produced by freezedrying. Both powdered samples had a notably high anthocyanin content and a low moisture content, hygroscopicity, $\mathrm{a}_{\mathrm{w}}$ and solubility. The powder formulated with MD 10DE had better results in 
all physicochemical analyses and was significantly different from the 20DE powder. In addition, the powder produced with MD 10DE had a larger particle diameter than the MD 20DE powder, as well as the highest anthocyanin content, suggesting that the greater the mean diameter of the particle, the smaller the surface area available for possible degradation of the encapsulated bioactive. The findings indicate that it is possible to produce powders from a blackberry by-product extract with high anthocyanin retention by freezedrying, which, together with the microencapsulation, was able to retain a significant percentage of anthocyanin content once the raw material used was an agroindustrial by-product, which do not have a full content of biocompound. The product could have a promising application in the food industry as a natural pigment in functional foods, providing not only an attractive color but also possible health benefits.

\section{Acknowledgements}

Funding for this research was provided under the São Paulo State Research Foundation (FAPESP). Also, authors would like to acknowledge the Microscopy Electron Laboratory (São Paulo State University (UNESP), Araraquara, SP, Brazil) and the Biomaterial and Natural Polymers Laboratory (University of São Paulo (USP), Pirassununga, SP, Brazil).

\section{References}

Ahmed, M., Akter, M. S., Lee, J. C., \& Eun, J. B. (2010). Encapsulation by spray drying of bioactive components, physicochemical and morphological properties from purple sweet potato. LWT-Food Science and Technology, 43(9), 1307-1312.

AOAC. (2000). Official methods of analysis (17th ed.). Gaithersburg, MD: AOAC International.

Bakowska-Barczak, A. M., \& Kolodziejczyk, P. P. (2011). Black currant polyphenols: Their storage stability and microencapsulation. Industrial Crops and Products, 34 $1301-1309$.

Balasundram, N., Sundram, K., \& Samman, S. (2006). Phenolic compounds in plants and agri-industrial by-products: Antioxidant activity, occurrence, and potential uses. Food Chemistry, 99, 191-203.

Branco, I. G., Moraes, I. C. F., Argandoña, E. J. S., Madrona, G. S., Dos Santos, C Ruiz, A. L. T. G., et al. (2016). Influence of pasteurization on antioxidant and in vitro anti-proliferative effects of jambolan (syzygium cumini (1.) skeels) fruit pulp. Industrial Crops and Products, 89, 225-230.

Caliskan, G., \& Dirim, S. N. (2016). The effect of different drying processes and the amounts of maltodextrin addition on the powder properties of sumac extract powders. Powder Technology, 287, 308-314.

Cano-Chauca, M., Stringheta, P. C., Ramos, A. M., \& Cal-Vidal, J. (2005). Effect of the carriers on the microstrcuture of mango poder spray drying and its functiona characterization. Innovative Food Science \& Emerging Technologie, 6(4), 420-428.

Ceballos, A. M., Giraldo, G. I., \& Orrego, C. E. (2012). Effect of freezing rate on quality parameters of freeze dried soursop fruit pulp. Journal of Food Engineering, 111, 360-365.

Chen, C., Chi, Y. J., \& Xu, W. (2012). Comparisons on the functional properties and antioxidant activity of spray-dried and freeze-dried egg white protein hydrolysate. Food and Bioprocess Technology, 5, 2342-2352.

Fazaeli, M., Emam-Djomeh, Z., Ashtari, A. K., \& Omid, M. (2012). Effect of spray drying conditions and feed composition on the physical properties of black mulberry juice powder. Food and BioproductsProcessing, 90, 667-675.

Ferrari, C. C., Germer, S. P. M., \& Aguirre, J. M. (2012). Effects of spray-drying conditions on the physicochemical properties of blackberry powder. Drying Technology, 30, 154-163.

Franceschinis, L., Salvatori, D. M., Sosa, N., \& Schebor, C. (2014). Physical and functional properties of blackberry freeze-and spray-dried powders. Drying Technology, 32, 197-207.

Fuleki, T., Francis, F. J., \& Quantitative methods for anthocyanins 1. (1968). Extraction and determination of total anthocyanin in cranberries. Journal of Food Science, $33,72-77$.

Gauche, C., Malagoli, E. S., \& Luiz, M. T. B. (2010). Effect of pH on the copigmentation of anthocyanins from Cabernet Sauvignon grape extracts with organic acids. Scientia Agricola, 67(1), 41-46.

Gorinstein, S., Poovarodom, S., Leontowicz, H., Leontowicz, M., Namiesnik, J. Vearasilp, S., et al. (2011). Antioxidant properties and bioactive constituents of some rare exotic Thai fruits and comparison with conventional fruits: In vitro and in vivo studies. Food Research International, 44, 2222-2232.

Hou, Z., Qin, P., Zhang, Y., Cui, S., \& Ren, G. (2013). Identification of anthocyanins isolated from black rice (Oryza sativa L.) and their degradation kinetics. Food Research International, 50(2), 691-697.
Ivanovic, J., Tadic, V., Dimitrijevic, S., Stamenic, M., Petrovic, S., \& Zizovic, I. (2014). Antioxidant properties of the anthocyanin-containing ultrasonic extract from blackberry cultivar "CačanskaBestrna". Industrial Crops and Products, 53, 274-281.

Jafari, S. M., Assadpoor, E., He, Y., \& Bhandari, B. (2008). Encapsulation efficiency of food flavours and oils during spray drying. Drying Technology, 26, 816-835.

Jafari, S. M., Mahdavi-Khazaei, K., \& Hemmati-Kakhki, A. (2016). Microencapsulation of saffron petal anthocyanins with cress seed gum compared with Arabic gum through freeze drying. Carbohydrate Polymers, 140, 20-25.

Jiménez-Aguilar, D. M., Ortega-Regules, A. E., Lozada-Ramírez, J. D., PérezPérez, M. C. I., Vernon-Carter, E. J., \& Welti-Chanes, J. (2011). Color and chemical stability of spray-dried blueberry extract using mesquite gum as wall material. Journal of Food Composition and Analysis, 24, 889-894.

Kaume, L., Howard, L. R., \& Devareddy, L. (2011). The blackberry fruit: A review on its composition and chemistry, metabolism and bioavailability, and health benefits. Journal of Agricultural and Food Chemistry, 60, 5716-5727.

Konczak, I., \& Zhang, W. (2004). Anthocyanins-more than nature's colours. BioMed Research International, 5, 239-240.

Kuck, L. S., \& Noreña, C. P. Z. (2016). Microencapsulation of grape (Vitislabrusca var. Bordo) skin phenolic extract using gum Arabic, polydextrose, and partially hydrolyzed guar gum as encapsulating agents. Food Chemistry, 194, 569-576.

Laokuldilok, T., \& Kanha, N. (2015). Effects of processing conditions on powder properties of black glutinous rice (Oryza sativa L.) bran anthocyanins produced by spray drying and freeze drying. LWT-Food Science and Technology, 64, 405-411.

Machado, A. P. D. F., Pasquel-Reátegui, J. L., Barbero, G. F., \& Martínez, J. (2015). Pressurized liquid extraction of bioactive compounds from blackberry (Rubus fruticosus L.) residues: A comparison with conventional methods. Food Research International, 77, 675-683.

Mahdavi, S. A., Jafari, S. M., Assadpoor, E., \& Dehnad, D. (2016). Microencapsulation optimization of natural anthocyanins with maltodextrin, gum Arabic and gelatin. International Journal of Biological Macromolecules, 85, 379-385.

Man, Y. B., Irwandi, J., \& Abdullah, W. J. W. (1999). Effect of different types of maltodextrin and drying methods on physico-chemical and sensory properties of encapsulated durian flavour. Journal of the Science of Food and Agriculture, 79, 1075-1080.

Nayak, C. A.. \& Rastogi, N. K. (2010). Effect of selected additives on microencapsulation of anthocyanin by spray drying. Drying Technology, 28, 1396-1404.

Nielsen, S. S., Marcy, J. E., \& Sadler, G. D. (1993). Chemistry of aseptically processed foods. In J. V. Chambers, \& P. E. Nelson (Eds.), Principles of aseptic processing and packaging (p. 87e114). Washington, DC: Food Processors Institute.

Oberoi, D. P. S., \& Sogi, D. S. (2015). Effect of drying methods and maltodextrin concentration on pigment content of watermelon juice powder. Journal of Food Engineering, 165, 172-178.

Paim, D. R., Costa, S. D., Walter, E. H., \& Tonon, R. V. (2016). Microencapsulation of probiotic jussara (Euterpe edulis M.) juice by spray drying. LWT-Food Science and Technology, 74, 21-25.

Patras, A. Brunton, N. P. O'Donnell, C. \& Tiwari, B. K. (2010). Effect of thermal processing on anthocyanin stability in foods; mechanisms and kinetics of degradation. Trends in Food Science \& Technology, 21, 3-11.

Quek, S. Y., Chok, N. K., \& Swedlund, P. (2007). The physicochemical properties of spray-dried watermelon powders. Chemical Engineering and Processing: Process Intensification, 46, 386-392.

Rocha-Parra, D. F., Lanari, M. C., Zamora, M. C., \& Chirife, J. (2016). Influence of storage conditions on phenolic compounds stability, antioxidant capacity and colour of freeze-dried encapsulated red wine. LWT-Food Science and Technology, $70,162-170$.

Roos, Y. (1995). Characterization of food polymers using state diagrams. Journal of Food Engineering, 24(3), 339-360.

Saikia, S., Mahnot, N. K., \& Mahanta, C. L. (2015). Optimisation of phenolic extraction from Averrhoacarambola pomace by response surface methodology and its microencapsulation by spray and freeze drying. Food Chemistry, 171, 144-152.

Silva, G. J. F. D., Constant, P. B. L., Figueiredo, R. W. D., \& Moura, S. M. (2010). Formulation and stability of anthocyanins's colorants formulated with peels jabuticaba (Myrciaria ssp.). Alimentos e Nutrição, 21, 429-436.

Souza, A. C. P., Gurak, P. D., \& Marczak, L. D. F. (2017). Maltodextrin, pectin and soy protein isolate as carrier agents in the encapsulation of anthocyanins-rich extract from jaboticaba pomace. Food and Bioproducts Processing, 102, 186-194.

Souza, V. B., Thomazini, M., Balieiro, J. C. C. \& Fávaro-Trindade, C. S. (2015). Effect of spray-dryingon the physicochemical properties and color stability of the powdered pigment obtained from vinification byproducts of the Bordo grape (Vitislabrusca). Food and Bioproducts Processing, 93, 39-50.

Syamaladevi, R. M., Insan, S. K., Dhawan, S., Andrews, P., \& Sablani, S. S. (2012). Physicochemical properties of encapsulated red raspberry (Rubusidaeus) powder: Influence of high-pressure homogenization. Drying Technology, 30, 484-493.

Tadeu, M. H., Souza, F. B. M. D., Pio, R., Valle, M. H. R. D., Locatelli, G., Guimarães, G. F., et al. (2015). Drastic summer pruning and production of blackberry cultivars in subtropical areas. Pesquisa Agropecuária Brasileira, 50(2), 132-140.

Tonon, R. V., Brabet, C., \& Hubinger, M. D. (2008). Influence of process conditions on the physicochemical properties of açai (Euterpe oleraceae Mart.) powder produced by spray drying. Journal of Food Engineering, 88, 411-418.

Tonon, R. V., Brabet, C., \& Hubinger, M. D. (2010). Anthocyanin stability and antioxidant activity of spray-dried açai (Euterpe oleracea Mart.) juice produced with 
different carrier agents. Food Research International, 43, 907-914.

Tonon, R. V., Freitas, S. S., \& Hubinger, M. D. (2011). Spray drying of açai (Euterpe oleraceae Mart.) juice: Effect of inlet air temperature and type of carrier agent. Journal of Food Processing and Preservation, 35(5), 691-700.

Tosun, I., Ustun, N. S., \& Tekguler, B. (2008). Physical and chemical changes during ripening of blackberry fruits. Scientia Agricola, 65(1), 87-90.

Wilkowska, A. Ambroziak, W., Czyżowska, A., \& Adamiec, J. (2016). Effect of microencapsulation by spray-drying and freeze-drying technique on the antioxidant properties of blueberry (Vacciniummyrtillus) juice polyphenolic compounds. Polish Journal of Food and Nutrition Sciences, 66(1), 11-16. 